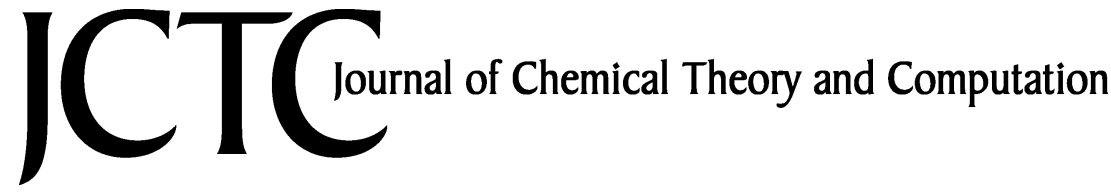

\section{Theoretical Investigation of Excited States of Large Polyene Cations as Model Systems for Lightly Doped Polyacetylene}

\author{
Ulrike Salzner* \\ Department of Chemistry, Bilkent University, 06800 Bilkent, Ankara, Turkey
}

Received July 6, 2006

\begin{abstract}
Electronic excitations of polyene cations with chain lengths of up to $101 \mathrm{CH}$ units were investigated as model systems for lightly doped polyacetylene (PA). Since high level ab initio calculations such as complete active space perturbation theory (CASPT2) are limited to systems with about $14 \mathrm{CH}$ units, the performances of time-dependent Hartree-Fock (TDHF) and time-dependent density functional theory (TDDFT) were evaluated. It turned out that TDDFT excitations energies are much more accurate for polyene cations than for neutral polyenes. The difference between TDHF and TDDFT excitation energies for the first allowed excited state of $\mathrm{C}_{49} \mathrm{H}_{51}{ }^{+}$is only $0.30 \mathrm{eV}$ with pure DFT and $0.21 \mathrm{eV}$ with a hybrid functional. For open-shell systems, pure DFT is found to be superior to DFT-hybrid functionals because it does not suffer from spin-contamination. Pure TDDFT excitation energies and oscillator strengths for small openshell polyene cations compare well with high level ab initio results. Excitation energies are found to be almost independent of the geometry, i.e., the size of the defect. Localization of the defect, however, shifts oscillator strengths from the HOMO-LUMO transition to higher lying excited states of the same symmetry. Lightly doped PA is predicted to exhibit several strong absorptions below $1 \mathrm{eV}$.
\end{abstract}

\section{Introduction}

Polyenes are model compounds for polyacetylene (PA) that can be used to investigate intrachain contributions to optical and electronic properties of conducting polymers. PA (Scheme 1) is a semiconductor that increases its conductivity to $10^{5} \mathrm{~S} / \mathrm{cm}$ when it is oxidized or $\mathrm{p}$-doped. ${ }^{1}$ The changes induced during doping can be monitored by in situ UVspectroscopy. Undoped PA has a strong absorption peak at $1.9 \mathrm{eV}$, which is attributed to an intrachain $\pi-\pi^{*}$-transition. Upon doping with iodine or arsenic pentafluoride, a new broad band between 0.65 and $0.75 \mathrm{eV}$ appears, while the intraband transition at $1.9 \mathrm{eV}$ decreases in intensity. ${ }^{2}$ There is no shift of the $\pi-\pi^{*}$-transition during doping. ${ }^{3}$ Effects of donor doping with $\mathrm{Na}$ are indistinguishable form those of acceptor doping. ${ }^{4}$

Heterocyclic conjugated organic polymers such as polythiophene (PT) and polypyrrole (PP) (Scheme 1) behave

\footnotetext{
* Corresponding author e-mail: salzner@fen.bilkent.edu.tr.
}

\section{Scheme 1}

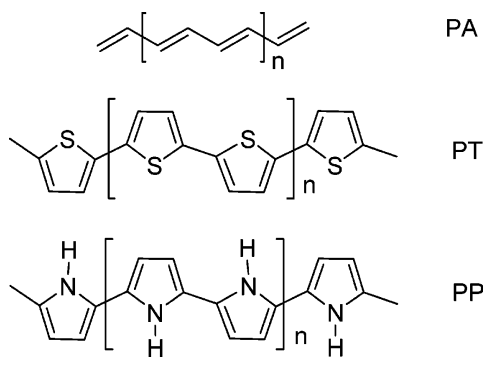

somewhat different. Doping with perchlorate leads to decrease of the intensity of the $\pi-\pi^{*}$-transition at $2.7 \mathrm{eV}$ of neutral PT and a shift of the interband transition to higher energy. At the same time two new features at $0.7-0.9$ and 1.5-1.8 eV are produced. ${ }^{5}$ Electrochemically produced PP is obtained in its oxidized form and shows two absorption bands at 1.0 and $2.7 \mathrm{eV}$. During reduction, a band appears at $3.6 \mathrm{eV}$ that moves to lower energy. The neutral polymer has its maximum absorbance at $3.2 \mathrm{eV} .{ }^{6}$ The shifting of the 
Scheme 2

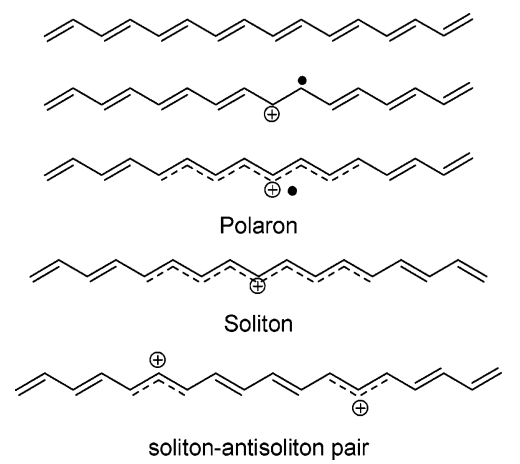

Scheme 3

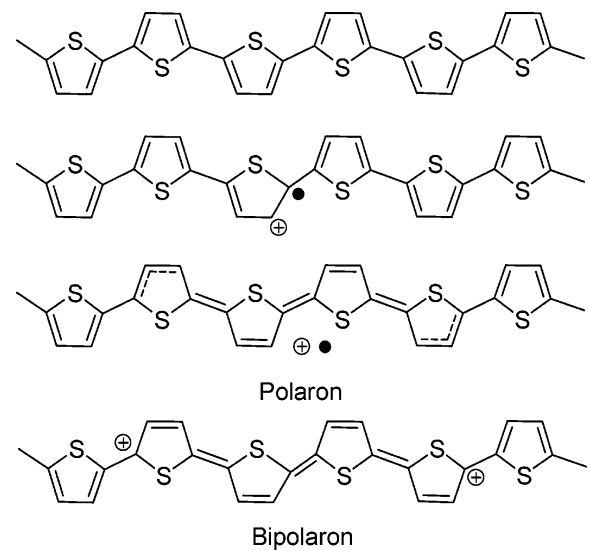

maximum absorption peak was rationalized by considering that the material is polydisperse and that shorter chains are reduced first. ${ }^{6}$

Optical properties of conducting polymers have been explained in terms of self-localized defects called solitons, polarons, and bipolarons. ${ }^{5,7-9}$ Solitons form only on polymers with degenerate ground states, such as PA. Degenerate ground state means that there is no energetic difference between the two forms, in which positions of single and double bonds are switched. Upon doping, solitons and soliton-antisoliton pairs are generated that are supposed to give rise to one interband transition in the optical spectrum (Scheme 2). Polymers with nondegenerate ground states such as PT and PP become quinoid when the positions of single and double bonds are exchanged (Scheme 3). Since quinoid forms are less stable for the neutral polymer, PT and PP do not form solitons but polarons and bipolarons (Scheme 3). Polarons are believed to be associated with three interband transitions, bipolarons with two., ${ }^{5,9}$ Since PT and PP develop two sub-band transitions upon doping and have very low ESR signals in the conducting state, they are assumed to form spinless bipolarons.

The existence of bipolarons has been questioned in experimental studies on polyene ${ }^{10}$ and on oligothiophene cations. ${ }^{11-14}$ Spectroscopic investigations in dilute solution show that dimers form at low temperature and that cations show two but dications only one absorption in the UV and near IR region. This is confirmed by high level ab initio studies of excited states of polyene ${ }^{15,16}$ and oligothiophene cations. ${ }^{16-18}$ Theoretical calculations, mostly employing semiempirical and Hartree-Fock methods, have confirmed the presence of self-localization in the presence and in the absence of counterions. ${ }^{19-34}$ At higher levels of theory, the size of the defects in the absence of counterions tends to increase $^{35}$ and bipolarons become unstable with respect to two polarons. ${ }^{36-38}$ As an alternative to bipolaron formation, $\pi$-dimers of radical cations have been shown to be stable when solvent effects are included in the theoretical treatment. ${ }^{39,40}$

Since experimental and theoretical studies raise some doubt about the nature of the sub-band transitions in doped conducting polymers and since high level theoretical investigations were carried out only up to decapentaene and terthiophene cations, it seems worthwhile to have a fresh look at optical properties of conducting polymers employing $\mathrm{ab}$ initio methods and density functional theory (DFT). The aim is to investigate effects of doping on the geometry and electronic structure and to analyze the influence of geometry changes on UV spectra of long oligomers with degenerate and with nondegenerate ground states. Finally the question why PA shows one sub-band feature in the UV spectrum while most other conducting polymers show two is addressed. Toward this aim detailed investigations of positively and negatively charged polyenes, thiophene and pyrrole oligomers in the absence and in the presence of counterions were initiated. Self-localization is investigated on longer oligomers than previously, and the effect of localization on excitation spectra is studied. In the present investigation an appropriate theoretical level for calculating excited states of long conjugated cations is searched for. It will be shown that time-dependent density functional theory (TDDFT), which was shown to be promising for open-shell systems, ${ }^{41}$ does not deteriorate for cations in the long chain limit as it does for neutral polyenes. ${ }^{42-47}$ Therefore polyene cations with chain lengths up to $\mathrm{C}_{101} \mathrm{H}_{103}{ }^{+}$could be treated. It turned out that acetylene, thiophene, and pyrrole oligomer cations give rise to two low-energy transitions. The high-energy feature is strong; the low-energy feature is weak. The difference between PA and PT or PP is that only for PA the energy difference between highest occupied molecular orbital (HOMO) and lowest unoccupied molecular orbital (LUMO) is almost identical for $\alpha$ - and $\beta$-electrons in open-shell monocations. As a result, the intensity of the low-energy feature of PA is so small that the peak is invisible, and the spectrum shows only one sub-band transition. In this investigation acetylene oligomers are discussed in detail. Oligothiophenes, oligopyrroles, dications, and n-doped species will be considered in forthcoming publications.

\section{Methods}

Polyene cations were investigated with DFT and with ab initio methods. Only one kind of basis set, Stevens-BaschKrauss pseudopotentials in combination with polarized split valence basis set (CEP-31G*) ${ }^{48-50}$ was used throughout. This basis set has been tested extensively and has been shown to yield reliable results for geometries and excited states of neutral polyenes as well as other conjugated oligomers. ${ }^{43,51-54}$ As cations and excited states of cations have compact electron densities, ${ }^{15}$ this basis set is sufficient for all properties of interest in the present investigation. 
Table 1. Bond Lengths of $\mathrm{C}_{13} \mathrm{H}_{15}$ and $\mathrm{C}_{14} \mathrm{H}_{16}$ Starting at the Chain Ends at Different Levels of Theory

\begin{tabular}{|c|c|c|c|c|c|c|c|}
\hline \multicolumn{2}{|c|}{ CASSCF } & \multicolumn{2}{|c|}{ pure DFT } & \multicolumn{2}{|c|}{ DFT-hybrid } & \multicolumn{2}{|c|}{ MP2 } \\
\hline $\mathrm{C}_{13} \mathrm{H}_{15}$ & $\mathrm{C}_{14} \mathrm{H}_{16}$ & $\mathrm{C}_{13} \mathrm{H}_{15}$ & $\mathrm{C}_{14} \mathrm{H}_{16}$ & $\mathrm{C}_{13} \mathrm{H}_{15}$ & $\mathrm{C}_{14} \mathrm{H}_{16}$ & $\mathrm{C}_{13} \mathrm{H}_{15}$ & $\mathrm{C}_{14} \mathrm{H}_{16}$ \\
\hline 1.373 & 1.370 & 1.387 & 1.382 & 1.371 & 1.363 & 1.356 & 1.377 \\
\hline 1.469 & 1.475 & 1.455 & 1.461 & 1.449 & 1.460 & 1.464 & 1.469 \\
\hline 1.385 & 1.375 & 1.406 & 1.396 & 1.391 & 1.373 & 1.382 & 1.385 \\
\hline 1.451 & 1.471 & 1.438 & 1.450 & 1.429 & 1.451 & 1.435 & 1.459 \\
\hline 1.403 & 1.376 & 1.417 & 1.400 & 1.405 & 1.376 & 1.402 & 1.388 \\
\hline \multirow[t]{2}{*}{1.428} & 1.469 & 1.427 & 1.447 & 1.416 & 1.448 & 1.417 & 1.457 \\
\hline & 1.376 & & 1.401 & & 1.377 & & 1.389 \\
\hline
\end{tabular}

For ab initio calculations, Møller-Plesset perturbation theory $^{55}$ up to second order (MP2) and the complete-active-

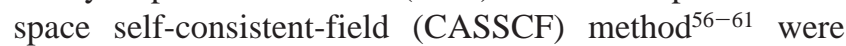
employed. The size-limit for CASSCF for us is 14 electrons and 14 orbitals for closed-shell systems and 13 electrons and 13 orbitals for open-shell species. For the largest evennumbered open-shell cation $\mathrm{C}_{14} \mathrm{H}_{16}{ }^{+}$that could be treated, it was therefore necessary to remove the highest unoccupied $\pi$-orbital from the active space. Comparison with $\mathrm{C}_{12} \mathrm{H}_{14}{ }^{+}$ that could be treated fully shows that the error introduced by using the limited active space is small. With MP2 our size limit is around $\mathrm{C}_{45} \mathrm{H}_{47}{ }^{+}$for closed-shell species. With DFT it is possible to optimize species with well over 100 $\mathrm{CH}$ units, so that all structures and defects are converged with respect to chain length.

For DFT calculations, two types of functionals were compared. For closed-shell systems, Becke's three-parameter hybrid functional ${ }^{62}$ with $30 \%$ of Hartree-Fock exchange ${ }^{53}$ combined with Perdew's 86 correlation functional (P86) ${ }^{63}$ works well. Because of problems with spin-contamination, excitation energies of open-shell species are better modeled without Hartree-Fock exchange. For these calculations, Becke's gradient corrected functional ${ }^{64}$ combined with P86 was used. The two functionals will be referred to as B3P86$30 \%$ or DFT-hybrid and BP86 or pure DFT. Excited-state calculations were carried out at the time-dependent HartreeFock (TDHF) and (TDDFT) levels. ${ }^{42,65-67}$ TDHF and TDB3P86-30\% excited-state calculations were done on the same geometries, optimized at B3P86-30\%/CEP-31G* since there is a dependence of excitation energies on bond length alternation (BLA). Since HF overestimates BLA, ${ }^{68}$ excitation energies are overestimated when HF geometries are used. ${ }^{44}$ Pure-DFT calculations on cations are based on BP86 and on B3P86-30\% geometries. All calculations were carried out with Gaussian 03 revisions $\mathrm{C} 0.2^{69}$ and D0.1.70

\section{Results and Discussion}

Geometries. Neutral Polyenes. To compare the performance of CASSCF, MP2, and DFT for open- and closed-shell systems, $\mathrm{C}_{13} \mathrm{H}_{15}$ and $\mathrm{C}_{14} \mathrm{H}_{16}$ were optimized in their neutral states (Table 1 ). For the CASSCF calculation all $\pi$-orbitals and $\pi$-electrons are included in the active space. CASSCF includes only nondynamic correlation, MP2 includes mainly dynamic correlation, and DFT accounts for some of both. For closed-shell systems, MP2 should be the best of the three methods, since it is known to give excellent geometries for closed-shell ground states. ${ }^{71}$ For open-shell species, MP2 is not reliable because it is based on the spin-contaminated HF wave function. Pure DFT is known to underestimate bond lengths alternation (BLA) ${ }^{68,72-74}$ but does not suffer from spin-contamination. Hybrid functionals are extremely popular since many of the shortcomings of pure DFT can be ameliorated by adding a certain amount of $\mathrm{HF}$ exchange. The most used hybrid functional is $\mathrm{B} 3^{62}$ which contains $20 \%$ of HF exchange. However, B3 in connection with LeeYang-Parr $(\mathrm{LYP})^{75}$ correlation functional was found to generate excessively delocalized defects on PA chains. ${ }^{35}$ It has also been shown previously that increasing the amount of HF exchange improves the performance of DFT-hybrid with respect to band gaps. ${ }^{52,53,68}$ Therefore $30 \%$ of $\mathrm{HF}$ exchange will be used throughout.

With DFT single and double bond lengths are both about $0.01 \AA$ shorter than with MP2. Double bond lengths are actually similar to those at CASSCF. Pure DFT produces identical single bond lengths compared to DFT-hybrid but longer double bonds. There are no experimental data for $\mathrm{C}_{13} \mathrm{H}_{15}$ and $\mathrm{C}_{14} \mathrm{H}_{16}$. For hexatriene and octatetraene the experimental central double lengths are $1.368 \AA$ and between 1.327 and $1.354 \AA$ according to Choi et al. ${ }^{68}$ That the double bond in octatetraene is shorter than in hexatriene is counterintuitive and indicates that there might be substantial experimental uncertainty. The DFT-hybrid/CEP-31G* values are 1.368 and $1.371 \AA$. The experimental single bond values are 1.457 for hexatriene and between 1.435 and $1.451 \AA$ for octatetraene. ${ }^{68}$ The DFT-hybrid/CEP-31G* values are 1.463 and $1.455 \AA$. Thus the present DFT-hybrid geometries are in reasonable agreement with experiment, theoretical bond lengths tending to be a bit longer.

Comparing results at CASSCF and MP2 levels for closedshell $\mathrm{C}_{14} \mathrm{H}_{16}$ shows that BLA is overestimated at CASSCF (0.093 $\AA$ ) compared to MP2 (0.068 §). The difference arises in equal amounts from shorter single and longer double bonds. With DFT-hybrid, BLA (0.071 $\AA$ ) is similar to that at MP2. For long polyenes, BLA converges to $0.058 \AA$ with MP2, to $0.062 \AA$ with DFT-hybrid, and to 0.023 with pure DFT. The experimental value for PA is about $0.08 \AA{ }^{76,77}$

Comparing open-shell $\mathrm{C}_{13} \mathrm{H}_{15}$ with closed-shell $\mathrm{C}_{14} \mathrm{H}_{16}$ at the CASSCF level indicates that radicals have longer double and shorter single bonds than closed-shell polyenes. The difference for $\mathrm{C}_{13} \mathrm{H}_{15}$ and $\mathrm{C}_{14} \mathrm{H}_{16}$ is $0.04 \AA$ for the terminal double bond. With the DFT-hybrid functional, the radical has a $0.08 \AA$ longer terminal double bond. In contrast, the terminal double bond contracts by $0.21 \AA$ at the MP2 level. The difference between CASSCF and DFT-hybrid is probably due to the more delocalized defect with DFT. The strong contraction of the double bond at MP2 is unexpected. Considering the high spin contamination of the MP2 wave function for $\mathrm{C}_{13} \mathrm{H}_{15}$ with an expectation value of the $\left\langle S^{2}\right\rangle$ operator of 2.35 instead of 0.75 , the MP2 result seems unreliable.

Odd-Numbered Polyene Cations. Odd-numbered polyene cations were investigated in the absence and in the presence of one $\mathrm{Cl}_{3}{ }^{-}$counterion. $\mathrm{Cl}_{3}{ }^{-}$was chosen as a model for iodine doping, which involves $\mathrm{I}_{3}{ }^{-}$and $\mathrm{I}_{5}{ }^{-}$ions. ${ }^{78} \mathrm{Cl}_{3}{ }^{-}$also forms during geometry optimization when three separate $\mathrm{Cl}$ 
Table 2. Bond Lengths of $\mathrm{C}_{13} \mathrm{H}_{15}{ }^{+}$and $\mathrm{C}_{14} \mathrm{H}_{16}{ }^{+}$Starting at the Chain Ends at Different Levels of Theory

\begin{tabular}{|c|c|c|c|c|c|c|c|}
\hline \multicolumn{2}{|c|}{ CASSCF } & \multicolumn{2}{|c|}{ pure DFT } & \multicolumn{2}{|c|}{ DFT-hybrid } & \multicolumn{2}{|c|}{ MP2 } \\
\hline $\mathrm{C}_{13} \mathrm{H}_{15}{ }^{+}$ & $\mathrm{C}_{14} \mathrm{H}_{16}{ }^{+}$ & $\mathrm{C}_{13} \mathrm{H}_{15}{ }^{+}$ & $\mathrm{C}_{14} \mathrm{H}_{16}{ }^{+}$ & $\mathrm{C}_{13} \mathrm{H}_{15}{ }^{+}$ & $\mathrm{C}_{14} \mathrm{H}_{16}{ }^{+}$ & $\mathrm{C}_{13} \mathrm{H}_{15}{ }^{+}$ & $\mathrm{C}_{14} \mathrm{H}_{16}{ }^{+}$ \\
\hline 1.372 & 1.374 & 1.386 & 1.389 & 1.367 & 1.374 & 1.382 & 1.355 \\
\hline 1.464 & 1.462 & 1.453 & 1.449 & 1.448 & 1.441 & 1.455 & 1.456 \\
\hline 1.385 & 1.389 & 1.406 & 1.411 & 1.387 & 1.397 & 1.399 & 1.382 \\
\hline 1.440 & 1.437 & 1.435 & 1.431 & 1.427 & 1.420 & 1.433 & 1.422 \\
\hline 1.398 & 1.403 & 1.417 & 1.420 & 1.401 & 1.407 & 1.410 & 1.403 \\
\hline \multirow[t]{2}{*}{1.417} & 1.415 & 1.425 & 1.425 & 1.413 & 1.411 & 1.420 & 1.415 \\
\hline & 1.406 & & 1.423 & & 1.410 & & 1.418 \\
\hline
\end{tabular}

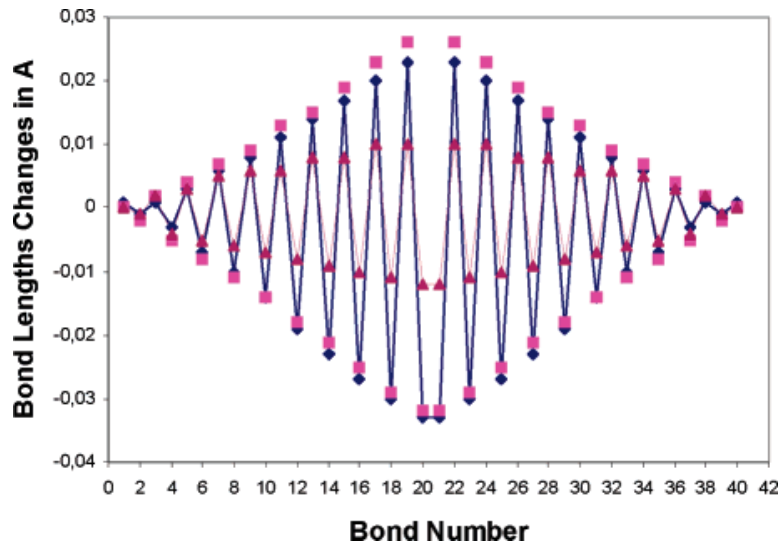

Figure 1. Changes in bond lengths of $\mathrm{C}_{41} \mathrm{H}_{43}{ }^{+}$compared to neutral $\mathrm{C}_{40} \mathrm{H}_{42}$ at MP2 (diamonds), DFT-hybrid (squares), and pure DFT (triangles) levels of theory.

atoms are placed next to chain. Only one kind of counterion was used here since experimental results ${ }^{2,4}$ as well as test calculations agree that changes upon doping are independent of the nature of the dopant ion. Odd-numbered polyene cations and polyene- $\mathrm{Cl}_{3}$ complexes are closed-shell singlets. Therefore MP2 geometries are expected to be reliable.

Geometries of $\mathrm{C}_{13} \mathrm{H}_{15}{ }^{+}$at CASSCF, pure DFT, DFThybrid, and MP2 are summarized in Table 2. Removing one electron from $\mathrm{C}_{13} \mathrm{H}_{15}$ converts the radical into a closed-shell cation. This change is associated with relatively small changes in bond lengths. Comparing data from Tables 1 and 2 shows that CASSCF, pure DFT, and DFT-hybrid agree that bond lengths tend to decrease upon ionization. The changes decrease in the order CASSCF $<$ DFT-hybrid < pure DFT. Only MP2 predicts substantial increases in certain bond lengths. This problem is caused by problems of MP2 with the $\mathrm{C}_{13} \mathrm{H}_{15}$ radical. Compared to MP2, CASSCF predicts longer single and shorter double bonds for $\mathrm{C}_{13} \mathrm{H}_{15}{ }^{+}$. This shows that dynamic correlation is necessary to predict accurate BLA. CASSCF geometries are therefore not very accurate but useful to evaluate closed- and open-shell systems on equal footing. Like for neutral polyenes, DFT-hybrid and MP2 predict similar BLA for $\mathrm{C}_{13} \mathrm{H}_{15}{ }^{+}$. MP2 and DFT-hybrid are the methods of choice for closed-shell cations.

In Figures 1 and 2, changes in bond lengths compared to neutral $\mathrm{C}_{40} \mathrm{H}_{42}$ are plotted for $\mathrm{C}_{41} \mathrm{H}_{43}{ }^{+}$in the absence and in the presence of one $\mathrm{Cl}_{3}{ }^{-}$counterion at MP2/CEP-31G*, BP86-30\%/CEP-31G*, and BP86/CEP-31G* levels of theory. The counterion is placed in the molecular plane in the vicinity of the hydrogen atoms (Scheme 4), since this conformation

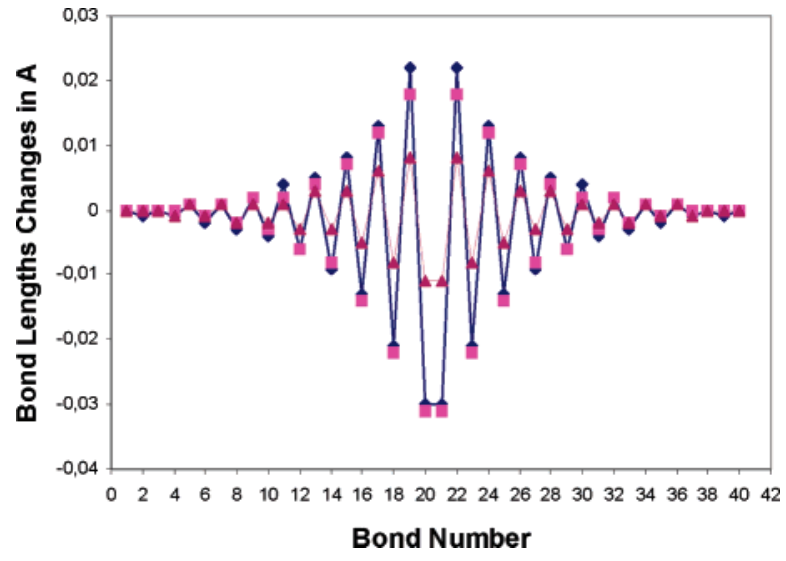

Figure 2. Changes in bond lengths of $\mathrm{C}_{41} \mathrm{H}_{43}-\mathrm{Cl}_{3}$ compared to neutral $\mathrm{C}_{40} \mathrm{H}_{42}$ at MP2 (diamonds), DFT-hybrid (squares), and pure DFT (triangles) levels of theory.

\section{Scheme 4}

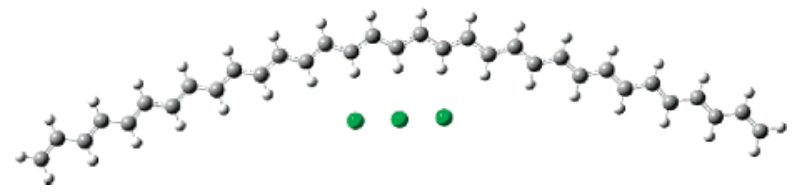

is lower in energy than the one with the counterion above the chain. The structures are fully optimized within $C_{2 v}$ symmetry. Charge transfer between polyene and counterion is virtually complete with natural populations $(\mathrm{NPA})^{79}$ of +0.97 e (MP2) and +0.96 e (DFT-hybrid) on the polyene chain. Figures 1 and 2 show that MP2 and DFT-hybrid lead to very similar changes in bond lengths. In the absence of a counterion, all bonds are involved in changes, but the major effect is observed at the center of the molecule. Pure-DFT gives a similar result at the chain ends and therefore a similar defect size. The response to charging in the middle of the chain is significantly less with pure DFT than with the other two methods. The reason for this is that neutral $\mathrm{C}_{40} \mathrm{H}_{42}$ is more delocalized with pure DFT, having BLA of only 0.023 $\AA$ (compared to $0.058 \AA$ and $0.062 \AA$ with MP2 and DFThybrid). Compared to DFT-hybrid the decreased BLA is due to longer double bonds.

In the presence of $\mathrm{Cl}_{3}{ }^{-}$, the defect is more localized. With MP2 the first five bonds are unaffected, with DFT, hybrid and pure, the first three bonds show no changes and the next four change very little. Defect sizes are therefore again similar with all three methods. At the center of the complex, DFT-hybrid leads to a slightly larger increase of the double 


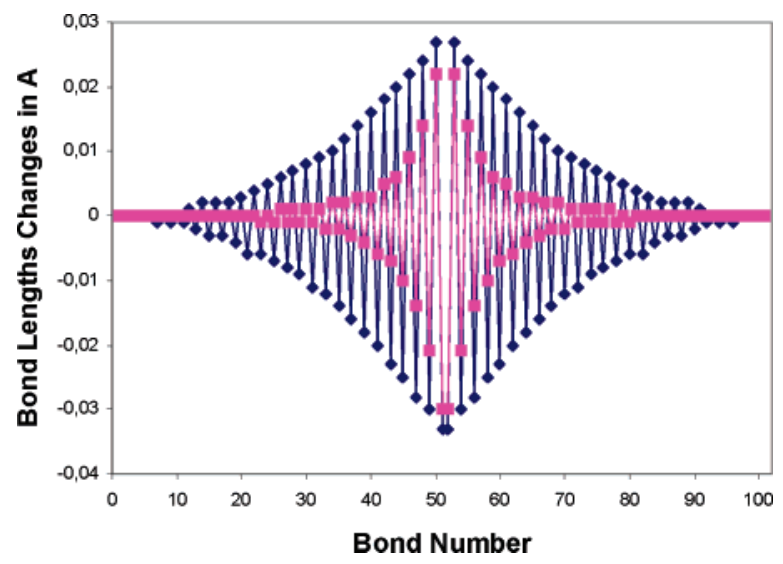

Figure 3. Changes in bond lengths of $\mathrm{C}_{101} \mathrm{H}_{103}{ }^{+}$(diamonds) and $\mathrm{C}_{101} \mathrm{H}_{103}-\mathrm{Cl}_{3}$ (squares) compared to neutral $\mathrm{C}_{102} \mathrm{H}_{104}$ with DFT-hybrid.

bond lengths than MP2, and pure DFT leads to a much smaller response because of the small BLA of $\mathrm{C}_{40} \mathrm{H}_{42}$.

The defect size in the absence of a counterion was determined to be about $36 \mathrm{CH}$ units at the MP2/6-31G level. B3LYP produced excessively delocalized defects. ${ }^{35}$ In contrast, DFT employing a hybrid functional with $30 \%$ of $\mathrm{HF}$ exchange provides similar defect sizes compared to MP2. For systems longer than $\mathrm{C}_{41} \mathrm{H}_{43}, \mathrm{MP} 2$ becomes prohibitively expensive, and DFT-hybrid geometries can be used without loss of accuracy. For example in Figure 3, the defect size is evaluated for $\mathrm{C}_{101} \mathrm{H}_{103}{ }^{+}$and $\mathrm{C}_{101} \mathrm{H}_{103}-\mathrm{Cl}_{3}$ at the DFT-hybrid level. For the naked cation, the first six bonds are completely unchanged compared to those in neutral $\mathrm{C}_{102} \mathrm{H}_{104}$. The next five bonds show negligible changes. Thus the defect spreads over about $80 \mathrm{CH}$ units in the absence of a counterion. With counterion, the first 21 bond lengths are identical with those in neutral $\mathrm{C}_{102} \mathrm{H}_{104}$. The next 10 bonds change by only $\pm 0.001 \AA$. This indicates that the defect size is about 40 $\mathrm{CH}$ units.

Since more localized defects are obtained with HF, MP2/ 6-31G, and with semiempirical methods ${ }^{7,16,20,23,29,35}$ and since forces during the geometry optimizations are very small, it seemed plausible that the differences are caused by very flat potential energy surfaces rather than the failure of certain methods. To investigate how big the energy lowering due to localization is, the counterions were removed, and single point energies were calculated on the geometries optimized in the presence of counterions. With DFT the energy difference is $1.66 \mathrm{kcal} / \mathrm{mol}$ for $\mathrm{C}_{33} \mathrm{H}_{35}{ }^{+}$and $1.89 \mathrm{kcal} / \mathrm{mol}$ for $\mathrm{C}_{41} \mathrm{H}_{43}{ }^{+}$. At the MP2 level, the energies of the $\mathrm{C}_{33} \mathrm{H}_{35}{ }^{+}$ with localized and delocalized defect differ by $2.14 \mathrm{kcal} /$ mol or $0.06 \mathrm{kcal} / \mathrm{mol}$ per $\mathrm{CH}$ unit. Thus a segment size of about $15 \mathrm{CH}$ units is required to obtain an energy difference of $1 \mathrm{kcal} / \mathrm{mol}$. Extremely high levels of theory are required, if chemical accuracy of $1 \mathrm{kcal} / \mathrm{mol}$ is to be achieved. It is therefore not surprising that semiempirical methods and $\mathrm{HF}$ theory give results that differ from those at higher theoretical levels. With energy differences that small, theoretical methods well beyond MP2 are required to give a final answer about the size of the defects. ${ }^{74}$ Such calculations are out of the question for systems long enough to have defect sizes converged with respect to chain lengths. The same sobering

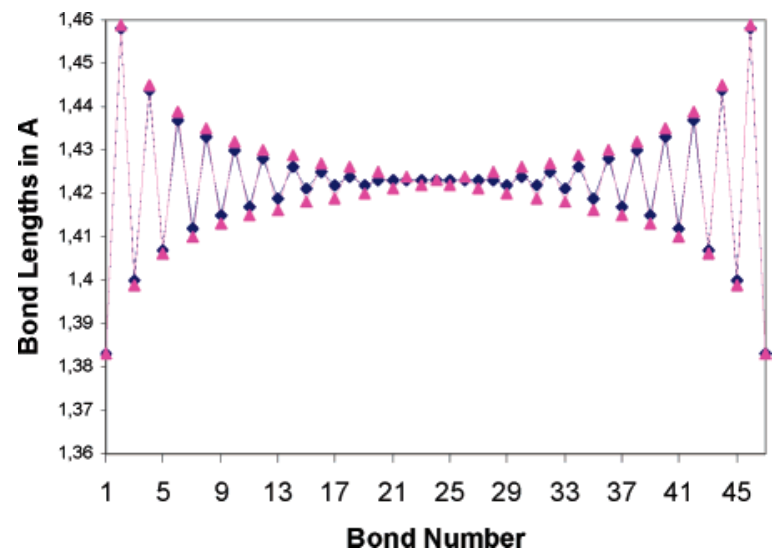

Figure 4. Bond lengths of $\mathrm{C}_{48} \mathrm{H}_{50}{ }^{+}$(diamonds) and $\mathrm{C}_{49} \mathrm{H}_{51}{ }^{+}$ (triangles) with pure DFT.

conclusion was drawn for neutral soliton defects in PA. ${ }^{80}$ Thus in contrast to the generally believed strong electron phonon coupling, ${ }^{27}$ high level ab initio calculations point toward very flat potential energy surfaces of doped conducting polymers.

Even-Numbered Polyene Cations. Calculating evennumbered long chain polyene cations is problematic at the MP2 level and with DFT-hybrid because spin-contamination increases dramatically with increasing chain length. CASSCF and pure DFT do not suffer from spin-contamination but the former overestimates, the latter underestimates BLA. Therefore, one should expect CASSCF and pure DFT to bracket the changes upon ionization. CASSCF calculations including $13 \pi$-electrons and $13 \pi$-orbitals in the active space were carried out for $\mathrm{C}_{14} \mathrm{H}_{16}{ }^{+}$. Results at CASSCF, pure DFT, DFThybrid, and MP2 are compared with those for $\mathrm{C}_{13} \mathrm{H}_{15}{ }^{+}$in Table 2.

Removing one electron form $\mathrm{C}_{14} \mathrm{H}_{16}$ converts a closedshell system to a radical cation. This leads to significant changes in bond lengths. CASSCF, pure DFT, and DFThybrid predict decrease in BLA, lengthening of the double bonds and shortening of the single bonds, especially in the center of the molecule. MP2 is the only method that predicts a shortening of the terminal double bond. Again MP2 shows erratic behavior for the radicals, which is most likely due to spin contamination. The spin expectation value for $\mathrm{C}_{14} \mathrm{H}_{16}{ }^{+}$ is 1.96 with MP2.

Comparing the geometries of $\mathrm{C}_{13} \mathrm{H}_{15}{ }^{+}$and $\mathrm{C}_{14} \mathrm{H}_{16}{ }^{+}$at CASSCF and pure DFT levels indicates that the first two bonds from the chain ends differ very little $\sim 0.002 \AA$. In the center $\mathrm{C}_{14} \mathrm{H}_{16}{ }^{+}$shows slightly larger BLA. The maximum difference between any two bond lengths is $0.005 \AA$ with both CASSCF and pure DFT. With DFT-hybrid, the trend is similar only the differences between $\mathrm{C}_{13} \mathrm{H}_{15}{ }^{+}$and $\mathrm{C}_{14} \mathrm{H}_{16}{ }^{+}$ are larger. Thus DFT-hybrid seems to work fairly well for short polyene cation radicals. The spin expectation value for $\mathrm{C}_{14} \mathrm{H}_{16}{ }^{+}$is 0.92 . Since spin contamination increases with chain length, DFT geometries were evaluated for longer oligomers. Bond lengths for open-shell $\mathrm{C}_{48} \mathrm{H}_{50}{ }^{+}$and closedshell $\mathrm{C}_{49} \mathrm{H}_{51}{ }^{+}$are summarized in Figure 4 (pure DFT) and Figure 5 (DFT-hybrid). Like for the shorter systems, pure DFT predicts very similar geometries for cation and radical cation. In contrast, the hybrid functional yields a totally 


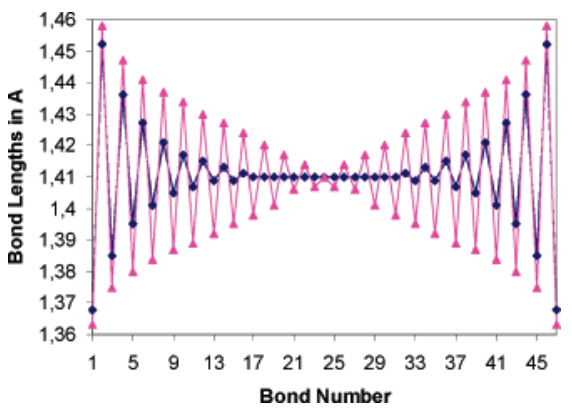

Figure 5. Bond lengths of $\mathrm{C}_{48} \mathrm{H}_{50}+$ (diamonds) and $\mathrm{C}_{49} \mathrm{H}_{51}{ }^{+}$ (triangles) with DFT-hybrid.

different geometry for $\mathrm{C}_{48} \mathrm{H}_{50}{ }^{+}\left(<S^{2}>=2.11\right)$ than for $\mathrm{C}_{49} \mathrm{H}_{51}{ }^{+}$. It is noteworthy that DFT-hybrid predicts a slightly larger defect for the radical cation than pure DFT. Since pure DFT is consistent with CASSCF for the small systems and since it does not suffer from spin contamination, the pure DFT result seems to be more reliable, although BLA is certainly underestimated.

Excitation Energies. Short polyenes ${ }^{81-83}$ and their cations ${ }^{15}$ have been investigated with high level ab initio methods such as CASPT2 and MRMP. The first optically allowed excited state of neutral polyenes has ${ }^{1} \mathrm{~B}_{\mathrm{u}}$ symmetry and is dominated by a single-electron (HOMO-LUMO) excitation. There is a second forbidden transition of ${ }^{1} \mathrm{~A}_{\mathrm{g}}$ symmetry that becomes the first excited state between hexatriene and octatetraene. The ${ }^{1} \mathrm{~A}_{\mathrm{g}}$ state is one-electron forbidden and includes double excitations. This state cannot be treated reliably with single electron methods ${ }^{39}$ and will not be considered here. Like neutral polyenes, odd-numbered cations have closed-shell ground states, and the first excitation energy to the ${ }^{1} \mathrm{~B}_{2}$ state is mainly due to a single-electron HOMO-LUMO transition. The first optically allowed excited state of radical cations is produced by two singleelectron transitions, one from the singly occupied molecular orbital (SOMO) to the LUMO and one from HOMO to SOMO. These two transitions correspond to separate HOMOLUMO transitions in $\alpha$ - and $\beta$-electron spaces of the openshell wavefunction. The two states mix with same and with opposite signs, generating a dipole-forbidden and a dipoleallowed excited state of ${ }^{2} \mathrm{~A}_{\mathrm{u}}$ or ${ }^{2} \mathrm{~B}_{\mathrm{g}}$ symmetry. ${ }^{15}$ As a result there are two features in the optical spectrum, the one at lower energy is weak (dipole-forbidden), the one at higher energy is dipole-allowed and has high intensity. ${ }^{84}$ The same state mixing happens between $\alpha$ - and $\beta$-electron transitions in closed-shell systems. The difference is that in a closed shell system, the cancellation is complete for the dipole forbidden state and its oscillator strength is exactly zero. For this reason neutral polyenes and odd-numbered cations show only one feature in the optical spectrum.

For neutral polyenes, the ${ }^{1} \mathrm{~B}_{\mathrm{u}}$ state is well described by TDHF. The results are of comparable accuracy to CASPT2 and MRMP predictions. ${ }^{43,44,85}$ TDDFT, pure as well as hybrid, increasingly underestimates excitation energies of conjugated systems with increasing chain length. ${ }^{42,45,46,86-88}$ Since high level ab initio methods become prohibitively expensive for long chain cations, TDHF and TDDFT will be tested here for excited-state calculations on polyene cations.

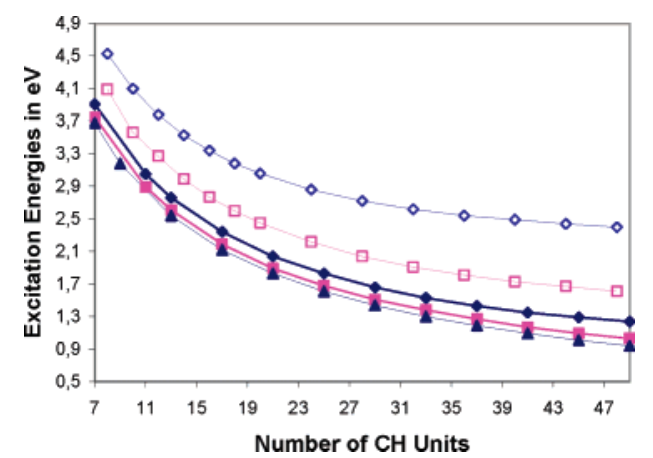

Figure 6. Excitation energies for neutral polyenes $\mathrm{C}_{8} \mathrm{H}_{10}-$ $\mathrm{C}_{48} \mathrm{H}_{50}$ (open symbols) and polyene cations $\mathrm{C}_{7} \mathrm{H}_{9}+-\mathrm{C}_{49} \mathrm{H}_{51}{ }^{+}$ (filled symbols) at TDHF (diamonds), TDDFT-hybrid (squares), and pure TDDFT (triangles).

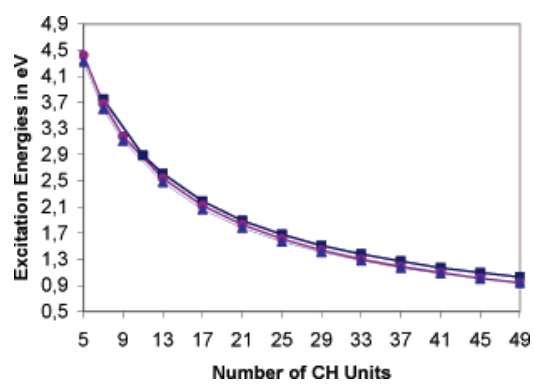

Figure 7. TDDFT-hybrid//DFT-hybrid (squares), pure TDDFT//DFT-hybrid (circles), and pure TDDFT//pure TDDFT (triangles) excitation energies for $\mathrm{C}_{5} \mathrm{H}_{7}{ }^{+}-\mathrm{C}_{49} \mathrm{H}_{51}{ }^{+}$.

Odd-Numbered Closed-Shell Polyene Cations. The first issue of interest is the behavior of TDHF and TDDFT excitation energies with increasing chain lengths. In Figure 6 excitation energies of neutral polyenes $\left(\mathrm{C}_{6} \mathrm{H}_{8}-\mathrm{C}_{48} \mathrm{H}_{50}\right)$ and of monocations $\left(\mathrm{C}_{5} \mathrm{H}_{7}{ }^{+}-\mathrm{C}_{45} \mathrm{H}_{47}{ }^{+}\right)$at TDHF, TDDFT-hybrid, and pure TDDFT levels are plotted versus chain length. In contrast to neutral polyenes, where the TDDFT excitation energies are too low and fall off too fast with increasing chain lengths, TDHF and TDDFT excitation energies and their chain length dependence are similar for cations. The difference between TDDFT-hybrid and TDHF excitation energies for $\mathrm{C}_{49} \mathrm{H}_{51}{ }^{+}$is $0.21 \mathrm{eV}$ as compared to $0.79 \mathrm{eV}$ for neutral $\mathrm{C}_{48} \mathrm{H}_{50}$. Moreover, there is very little difference between results with the hybrid functional and with pureTDDFT $(0.09 \mathrm{eV})$. This is investigated in more detail in Figure 7, where TDDFT excitation energies are plotted vs chain lengths using TDDFT-hybrid, pure TDDFT on the hybrid geometry, and finally pure TDDFT on the pure DFT geometry. That the three curves lie almost on top of one another shows that HF exchange has little influence on TDDFT excitation energies and that the geometry does not influences the $1{ }^{1} \mathrm{~B}_{\mathrm{u}}$ excitation energies either. Thus TDHF and TDDFT, pure and hybrid, appear to be reliable for calculating $1{ }^{1} \mathrm{~B}_{\mathrm{u}}$ excitation energies of closed-shell cations even at long chain lengths.

Even-Numbered Open-Shell Polyene Cations. The preceding chapters have revealed that DFT geometries of openshell systems have defect sizes which are too delocalized with DFT-hybrid. The comparison of excitation energies based on DFT-hybrid and pure DFT geometries for closedshell cations has shown, however, that employing delocalized 


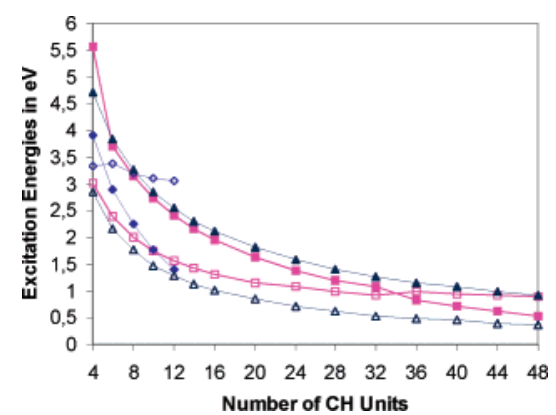

Figure 8. Excitation energies for $\mathrm{C}_{4} \mathrm{H}_{8}{ }^{+}-\mathrm{C}_{48} \mathrm{H}_{50}{ }^{+}$, dipoleforbidden states (open symbols), dipole-allowed states (filled symbols) at TDHF (diamonds), TDDFT-hybrid (squares), and pure TDDFT (triangles).

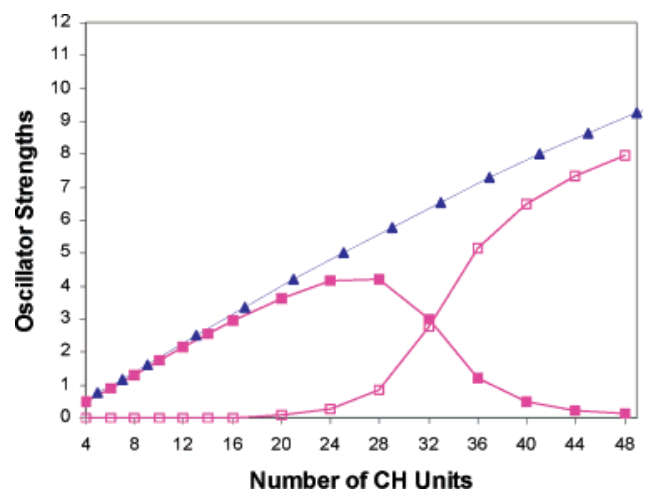

Figure 9. TDDFT-hybrid oscillator strengths for closed-shell cations $\mathrm{C}_{5} \mathrm{H}_{7}{ }^{+}-\mathrm{C}_{49} \mathrm{H}_{51}{ }^{+}$(triangles) and for open-shell cations $\mathrm{C}_{4} \mathrm{H}_{8}{ }^{+}-\mathrm{C}_{48} \mathrm{H}_{50}{ }^{+}$(squares).

pure DFT geometries does not influence the excitation energies very much (compare Figure 7). Therefore DFThybrid geometries were employed for the excited-state calculations.

In Figure 8 excitation energies at TDHF, TDDFT-hybrid, and pure TDDFT are presented for open-shell cations. The three methods find two excited states arising from the mixing of HOMO-SOMO and SOMO-LUMO transitions, as expected. However, TDHF predicts the correct order of oscillator strengths only for butadiene. For polyenes longer than butadiene, the lower energy excited state is intense and the higher one is weak. At the same time the energies of the two excited states are too close, underestimating the highenergy transition and overestimating the low-energy transition. The values deteriorate completely at longer chain lengths. In contrast, TDDFT, hybrid, and pure DFT, correctly predict lower oscillator strengths for the low-energy feature for short to medium sized polyenes up to $\mathrm{C}_{28} \mathrm{H}_{30}{ }^{+}$. At $\mathrm{C}_{32} \mathrm{H}_{34}{ }^{+}$ TDDFT-hybrid switches oscillator strengths of the two excited states. The dependence of oscillator strengths on chain lengths with hybrid and pure DFT functionals for evenand odd-numbered cations is shown in Figures 9 and 10.

It turns out that the crossover occurs with both TDHF and TDDFT-hybrid when the expectation value of the spin operator exceeds a value of 1 . The value for a pure doublet state is 0.75 . Thus, the relative oscillator strengths of the two transitions exchange when the wavefunction acquires increasing triplet character. As mentioned above, the two low-energy excitations of polyene cations arise from coupling

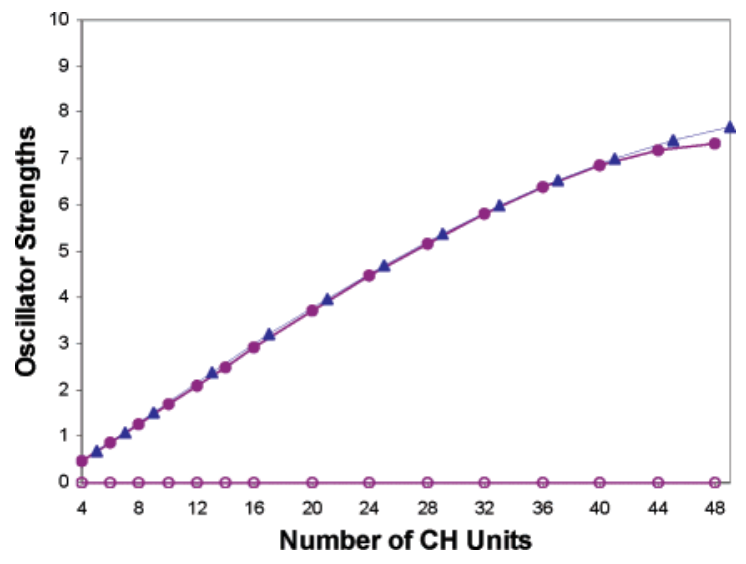

Figure 10. Pure TDDFT oscillator strengths for closed-shell cations $\mathrm{C}_{5} \mathrm{H}_{7}{ }^{+}-\mathrm{C}_{49} \mathrm{H}_{51}{ }^{+}$(triangles) and for open-shell cations $\mathrm{C}_{4} \mathrm{H}_{8}{ }^{+}-\mathrm{C}_{48} \mathrm{H}_{50}{ }^{+}$(circles).

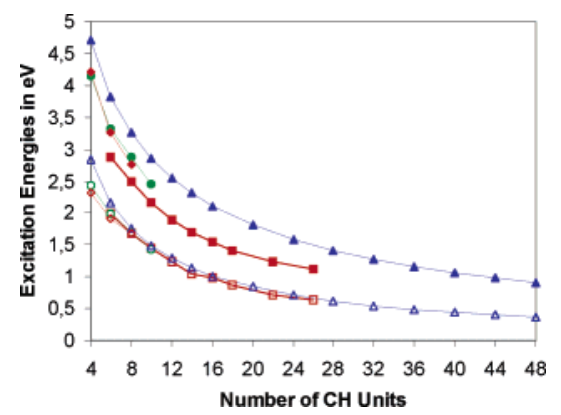

Figure 11. Excitation energies for $\mathrm{C}_{4} \mathrm{H}_{8}{ }^{+}-\mathrm{C}_{48} \mathrm{H}_{50}{ }^{+}$, dipoleforbidden states (open symbols), and dipole-allowed states (filled symbols). Experiment parent polyene cations (diamonds), experiment tert-butyl-capped polyene cations (squares), MRMP (circles), and pure TDDFT (triangles).

between the transitions of $\alpha$ - and $\beta$-electrons with the opposite sign (dipole-allowed) and with the same sign (dipole-forbidden). Since a triplet has two electrons with the same spin, the mixing of $\alpha$ - and $\beta$-excitations with same signs is dipole-allowed and mixing with opposite signs is dipole-forbidden. The spin contaminated wavefunction can therefore not be applied for calculating excitation energies and oscillator strengths. Pure DFT has no problem with spin contamination. The spin expectation value increases very slowly and reaches only 0.80 for $\mathrm{C}_{56} \mathrm{H}_{58}{ }^{+}$. No crossover between oscillator strengths occurs with pure TDDFT (Figure 10), confirming that the crossover is an artifact caused by spin-contamination.

In Figure 11 pure TDDFT excitation energies are compared with experiment and with MRMP results. Experimental data are measured by Bally et al. ${ }^{10,84}$ There are two sets of experimental data, parent polyene cations and tert-butyl capped systems. The weak absorption is very similar for both systems, but the strong peak occurs at lower energy for tertbutyl capped polyene cations. MRMP data are those of Kawashima et al. ${ }^{15}$ MRMP excitation energies reproduce experimental data for parent polyene cations very well. However, it should be kept in mind that experiments are done in matrix and that theoretical values are obtained in the gas phase. For neutral polyenes the solvent effect is $0.3-0.4$ $\mathrm{eV} .{ }^{89}$ Therefore one might expect accurate theoretical values to be a little higher than experimental ones. Interestingly, 
Table 3. TDDFT Excitation Energies in $\mathrm{eV}$ and Oscillator Strengths for Polyene Cations ${ }^{a}$

\begin{tabular}{lllll}
\hline & \multicolumn{1}{c}{$\mathrm{C}_{4} \mathrm{H}_{6}{ }^{+}$} & \multicolumn{1}{c}{$\mathrm{C}_{6} \mathrm{H}_{8}{ }^{+}$} & \multicolumn{1}{c}{$\mathrm{C}_{8} \mathrm{H}_{10}{ }^{+}$} & $\mathrm{C}_{10} \mathrm{H}_{12}{ }^{+}$ \\
\hline $\mathrm{E}(1)$ & $2.84(2.43)$ & $2.17(1.98)$ & $1.76(1.69)$ & $1.48(1.43)$ \\
osc. strength & $0.010(0.011)$ & $0.009(0.015)$ & $0.007(0.022)$ & $0.005(0.022)$ \\
$\mathrm{E}(2)$ & $4.71(4.16)$ & $3.83(3.32)$ & $3.26(2.88)$ & $2.86(2.46)$ \\
osc. strength & $0.475(0.626)$ & $0.858(0.998)$ & $1.260(1.380)$ & $1.679(1.706)$ \\
\hline
\end{tabular}

a MRMP values according to ref 15 are given in brackets.

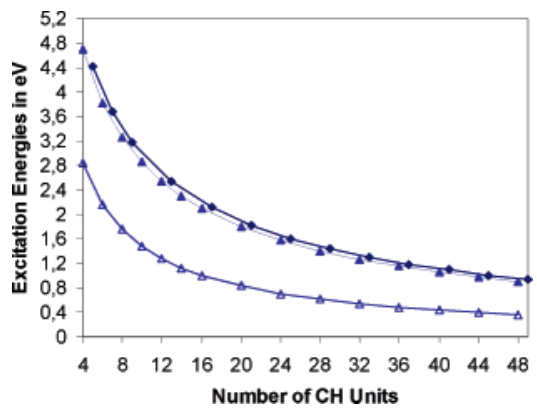

Figure 12. Comparison of excitation energies of open-shell (triangles) and closed shell (diamonds) cations with pure TDDFT.

the solvent effects for the butadiene and the hexatriene cations are reported to have opposite signs, increasing the excitation energy of butadiene but lowering the excitation energy of hexatriene by $0.2 \mathrm{eV} .^{84}$

Pure TDDFT excitation energies for the low-energy transition agree very well with MRMP data (Table 3) and with experiment. All data sets fall on top of each other. For the high-energy feature there are larger differences. TDDFT predicts higher excitation energies than MRMP, but the difference is acceptable $\sim 0.4-0.5 \mathrm{eV}$. The chain length dependence compared to the end-capped systems is also reasonable, although there is a tendency of TDDFT excitation energies of falling off too fast. Thus TDDFT, which is the only theoretical method that can be applied to large openshell systems, produces reasonable results compared to experiment and MRMP. (A note on the side: Since relative signs of $\alpha$ - and $\beta$-orbitals are random in unrestricted calculations, relative signs of $\alpha$ - and $\beta$-coefficients contributing to a certain excited state are also random. Thus the dipole allowed state might appear to be generated from the positive instead of the negative sign combination of $\alpha$ - and $\beta$-excitations with TDDFT. Plotting of the orbitals reveals that the $\alpha$ - and $\beta$-orbitals are mirror images of each other in such cases.)

In Figure 12 pure TDDFT excitation energies for closed and open-shell systems are plotted vs increasing number of $\mathrm{CH}$ units. In Figures 13 and 14 spectra are simulated for selected odd- and even-numbered polyene cations of comparable size. It is visible that excitation energies of the intense feature in open-shell and closed shell species are very similar when calculated with pure TDDFT. For instance, the excitation energies of the strong absorptions are 0.98 and $1.01 \mathrm{eV}$ for $\mathrm{C}_{44} \mathrm{H}_{46}{ }^{+}$and $\mathrm{C}_{45} \mathrm{H}_{47}{ }^{+}$, respectively. The same agreement was found for oscillator strength as shown in Figure 10. At all chain lengths the low-energy absorption has very small oscillator strength and is invisible in the spectra. For the longer species $\mathrm{C}_{40} \mathrm{H}_{42}{ }^{+}$and $\mathrm{C}_{41} \mathrm{H}_{43}{ }^{+}$, additional features appear at the long wavelengths side of the

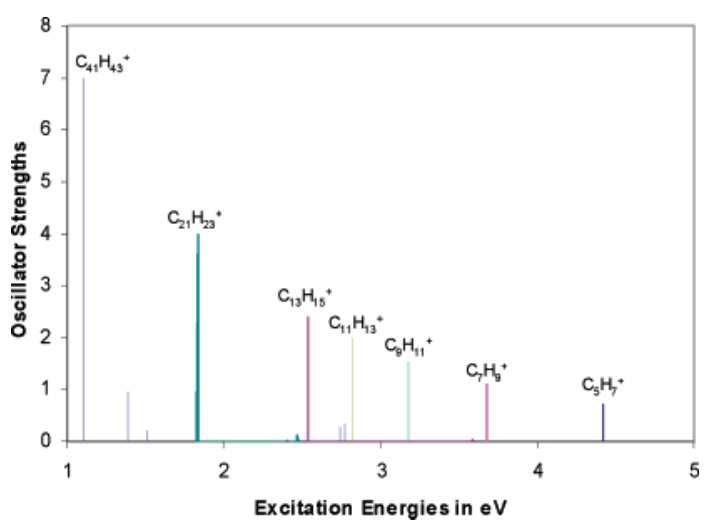

Figure 13. Simulated UV-spectra of odd-numbered closedshell polyene cations at the pure TDDFT level.

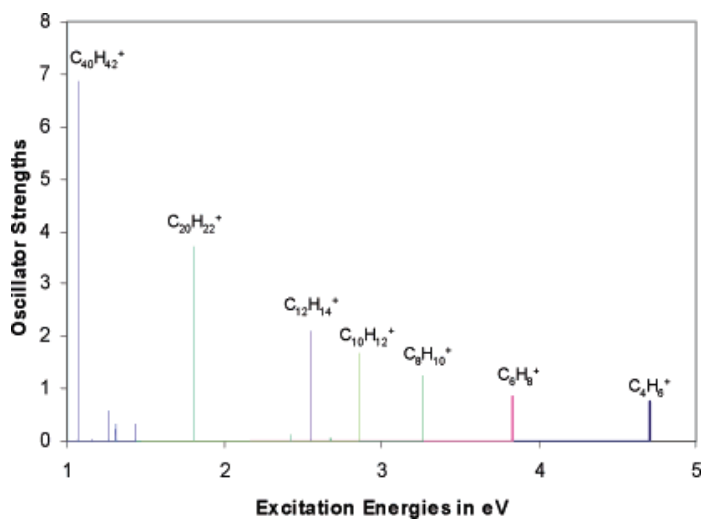

Figure 14. Simulated UV-spectra of even-numbered openshell polyene cations at the pure TDDFT level.

main peak. That there are more such features with openshell species might be due to slight differences in $\alpha$ - and $\beta$-orbital energy differences in unrestricted calculations. Overall spectra of even- and odd-numbered cations are predicted to differ little, which means that closed-shell oddnumbered cations are indeed very good models for doped PA and can be used to avoid the problems with spincontamination.

The almost complete cancellation of the oscillator strength of the weak absorption of open-shell cations can be understood by investigating the orbital energy levels for $\alpha$ and $\beta$-electrons. In Figures 15 and 16, DFT-hybrid $\pi$-orbital energies are plotted for closed-shell $\mathrm{C}_{13} \mathrm{H}_{15}{ }^{+}$through $\mathrm{C}_{101} \mathrm{H}_{103}{ }^{+}$ and open-shell $\mathrm{C}_{10} \mathrm{H}_{12}{ }^{+}$through $\mathrm{C}_{48} \mathrm{H}_{50}{ }^{+}$. In Figure 16, $\beta$-energy levels are slightly shifted right with respect to $\alpha$-energy levels. Short open-shell cations have very different energies for $\alpha$ - and $\beta$-electrons, $\beta$-levels lying lower in energy. As the chain lengths increases, these energy differences decrease as the $\beta$-LUMO, the orbital from which the electron has been removed, merges with the $\alpha$-LUMO. Likewise the $\alpha$ - and $\beta$-HOMO orbitals approach each other. 


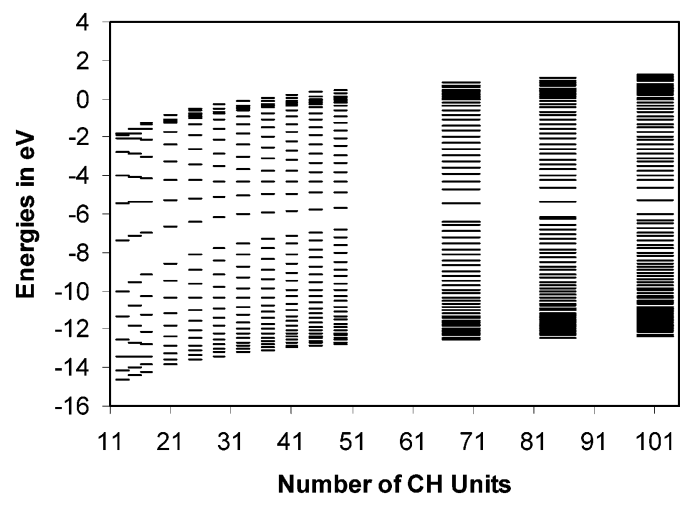

Figure 15. DFT-hybrid $\pi$-orbital energies for $\mathrm{C}_{13} \mathrm{H}_{15}{ }^{+-}$ $\mathrm{C}_{101} \mathrm{H}_{103}{ }^{+}$.

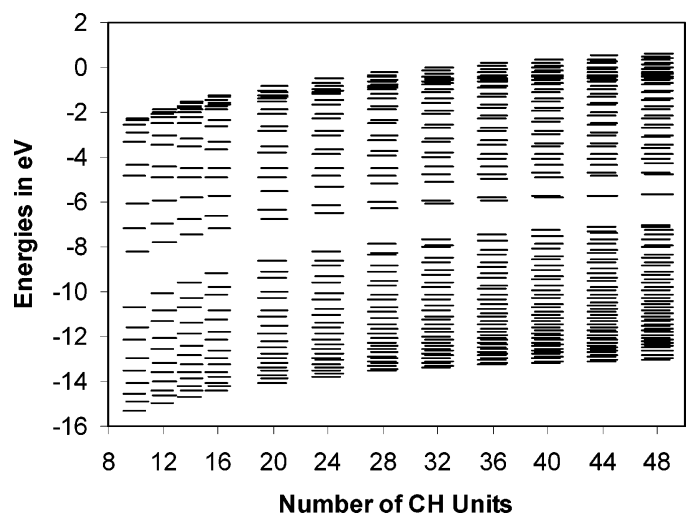

Figure 16. DFT-hybrid $\pi$-orbital energies for $\mathrm{C}_{10} \mathrm{H}_{12}{ }^{+}-$ $\mathrm{C}_{48} \mathrm{H}_{50}{ }^{+}$. Values of $\beta$-electrons offset to the right.

Despite the energy differences between $\alpha$ - and $\beta$-levels for short cations, the $\alpha$ and $\beta$ HOMO-LUMO gaps are almost identical at all chain lengths. Thus, like in closed-shell polyene cations, exciting $\alpha$ - and $\beta$-electrons require similar energies. For this reason, excitations are produced by mixing both states in almost equal amounts at all chain lengths. The equal mixing leads to the almost complete cancellation of the oscillator strength of the dipole-forbidden state and the resemblance of spectra of closed- and open-shell polyene cations. It will be shown in a forthcoming publication that such a cancellation does not occur with thiophene and pyrrole oligomer cations, which exhibit two absorptions of comparable strengths in the UV.

Comparing Figures 15 and 16 reveals that for long chains, closed- and open-shell polyene cations have very similar energy level patterns with one empty level lying slightly above the middle of the energy gap. This state moves to the middle of the gap in the long chain limit as is visible for $\mathrm{C}_{101} \mathrm{H}_{103}{ }^{+}$in Figure 15. For $\mathrm{C}_{101} \mathrm{H}_{103}{ }^{+}$, the HOMO-LUMO gap is $1.37 \mathrm{eV}$, and the midgap state lies $0.70 \mathrm{eV}$ above the HOMO. As discussed in the geometry section, the defect size for $\mathrm{C}_{101} \mathrm{H}_{103}{ }^{+}$is about $80 \mathrm{CH}$ units in the absence of a counterion. Thus geometric localization of the defect is not responsible for the midgap state.

Higher Lying Excited States. With increasing chain lengths additional ${ }^{1} \mathrm{~B}_{\mathrm{u}}$ and ${ }^{1} \mathrm{~B}_{2}$ states of decreasing energy and of increasing oscillator strength are predicted by TDDFT (compare Figures 13 and 14). There are also low lying excited states of other symmetries, but they have low
Table 4. ${ }^{1} \mathrm{~B}_{2}$ Excitation Energies in $\mathrm{eV}$ and Oscillator Strengths (in Brackets) for $\mathrm{C}_{49} \mathrm{H}_{51}{ }^{+}, \mathrm{C}_{69} \mathrm{H}_{71}{ }^{+}, \mathrm{C}_{85} \mathrm{H}_{87}{ }^{+}$, and $\mathrm{C}_{101} \mathrm{H}_{103}{ }^{+}$at TDDFT-Hybrid and Pure TDDFT Levels of Theory

\begin{tabular}{llllll}
\hline & & $\mathrm{C}_{49} \mathrm{H}_{51}{ }^{+}$ & $\mathrm{C}_{69} \mathrm{H}_{71}{ }^{+}$ & $\mathrm{C}_{85} \mathrm{H}_{87}{ }^{+}$ & $\mathrm{C}_{101} \mathrm{H}_{103}{ }^{+}$ \\
\hline $1^{1} \mathrm{~B}_{2}$ & hybrid & $1.03(9.29)$ & $0.79(11.65)$ & $0.68(11.94)$ & $0.58(10.96)$ \\
& pure & $0.94(7.70)$ & $0.68(8.34)$ & $0.55(7.92)$ & $0.44(7.79)$ \\
$2^{1} \mathrm{~B}_{2}$ & hybrid & $1.70(0.37)$ & $1.26(1.20)$ & $1.05(2.60)$ & $0.88(5.06)$ \\
& pure & $1.19(1.60)$ & $0.89(3.72)$ & $0.75(5.39)$ & $0.65(6.62)$ \\
$3^{1} \mathrm{~B}_{2}$ & hybrid & $2.06(0.08)$ & $1.68(0.08)$ & $1.47(0.01)$ & $1.25(0.32)$ \\
& pure & $1.31(0.39)$ & $1.00(1.24)$ & $0.86(2.05)$ & $0.76(2.80)$ \\
$4^{1} \mathrm{~B}_{2}$ & hybrid & $2.43(0.33)$ & $1.84(0.42)$ & $1.56(0.53)$ & $1.38(0.43)$ \\
& pure & $1.76(0.00)$ & $1.27(0.02)$ & $1.03(0.10)$ & $0.87(0.57)$ \\
$5^{1} \mathrm{~B}_{2}$ & hybrid & $2.61(0.60)$ & $2.04(0.99)$ & $1.77(1.35)$ & $1.59(2.08)$ \\
& pure & $1.93(0.02)$ & $1.43(0.08)$ & $1.18(0.24)$ & $1.02(0.48)$ \\
& & & & &
\end{tabular}

oscillator strength at all chain lengths. For the longest oddnumbered systems, two additional ${ }^{1} \mathrm{~B}_{2}$ states reach oscillator strengths comparable to that of the $1{ }^{1} \mathrm{~B}_{2}$ state. The first five ${ }^{1} \mathrm{~B}_{2}$ excitation energies are summarized for $\mathrm{C}_{49} \mathrm{H}_{51}{ }^{+}, \mathrm{C}_{69} \mathrm{H}_{71}{ }^{+}$, $\mathrm{C}_{85} \mathrm{H}_{87}{ }^{+}$, and $\mathrm{C}_{101} \mathrm{H}_{103}{ }^{+}$at TDDFT-hybrid and pure TDDFT levels in Table 4.

Although the $1{ }^{1} \mathrm{~B}_{2}$ states of closed-shell cations have almost the same energies with TDDFT-hybrid and pure TDDFT, the energies of higher lying ${ }^{1} \mathrm{~B}_{2}$ states differ with both DFT methods. Pure DFT predicts these excitation energies to be between $0.23-0.75 \mathrm{eV}$ lower in energy and their oscillator strengths to be larger. The differences decrease with increasing chain lengths. The reason for this difference seems to be that energy levels lie closer with pure DFT than with DFT-hybrid. Thus with pure TDDFT, the additional excited states become significant at shorter chain lengths. The only number for comparison, that is available for a higher lying excited state, is the $3{ }^{2} \mathrm{~B}_{\mathrm{g}}$ state of decapentaene, obtained with MRMP by Kawashima et al., ${ }^{15}$ which lies at $3.53 \mathrm{eV}$. For this state both DFT levels seem to work fine. Pure TDDFT predicts $3.52 \mathrm{eV}$, TDDFT-hybrid $3.73 \mathrm{eV}$ $\left(S^{2}=0.86\right)$. The pure TDDFT value is closer to the MRMP value, but one number is not sufficient to assess the performance of the two methods with certainty.

The decrease in energy of the higher ${ }^{1} B_{2}$ states with increasing chain lengths is consistent with the decrease in the spacing between energy levels (compare Figure 15). As the corresponding excitation energies are coming down, the corresponding states are becoming multiconfigurational. The first ${ }^{1} \mathrm{~B}_{2}$ state is still dominated by the HOMO-LUMO transition, but a second transition between HOMO-2 and LUMO gains importance with increasing chain length. $2{ }^{1} \mathrm{~B}_{2}$ is composed of two single electron transitions between HOMO-2 and LUMO and HOMO-1-LUMO+2. $3{ }^{1} \mathrm{~B}_{2}$ is composed of two contributions, HOMO-1-LUMO+1 and $\mathrm{HOMO}-\mathrm{LUMO}+2$. The energy spacing between the three states is 0.21 and $0.11 \mathrm{eV}$ for $\mathrm{C}_{101} \mathrm{H}_{103}{ }^{+}$with pure TDDFT and 0.30 and $0.37 \mathrm{eV}$ with TDDFT-hybrid.

Effect of Counterions. Depending on chain lengths of the polyene, energy levels of counterions may lie within the polyene band gap. For such systems, excitations from polyene to the counterions have very low energies but also low oscillator strengths. The main features in the UV-spectra 
Table 5. Pure TDDFT Excitation Energies (eV) of Polyene Cations and Polyene- $\mathrm{Cl}_{3}$ Complexes Based on Geometries with Increasingly Localized Defects

\begin{tabular}{lrrrr}
\hline & & & \multicolumn{2}{c}{ B3P86-30\% complex } \\
\cline { 3 - 5 } geometry & BP86 & B3P86-30\% & no counterion & with $\mathrm{Cl}_{3}{ }^{-}$ \\
\hline & & $\mathrm{C}_{41} \mathrm{H}_{43}{ }^{+}$ & & \\
$1^{1} \mathrm{~B}_{2}$ & $1.08(8.00)$ & $1.10(7.00)$ & $1.05(5.36)$ & $1.14(4.75)$ \\
$2{ }^{1} \mathrm{~B}_{2}$ & $1.32(0.28)$ & $1.39(0.95)$ & $1.39(1.59)$ & $1.18(0.62)$ \\
$3{ }^{1} \mathrm{~B}_{2}$ & $1.39(0.12)$ & $1.51(0.21)$ & $1.54(0.47)$ & $1.50(1.55)$ \\
& & $\mathrm{C}_{69} \mathrm{H}_{71}{ }^{+}$ & & \\
$1^{1} \mathrm{~B}_{2}$ & & $0.68(8.34)$ & $0.62(5.92)$ & $0.75(4.05)$ \\
$2{ }^{1} \mathrm{~B}_{2}$ & & $0.89(3.72)$ & $0.91(3.67)$ & $0.77(1.92)$ \\
$3{ }^{1} \mathrm{~B}_{2}$ & & $1.00(1.24)$ & $1.04(1.57)$ & $1.04(4.73)$ \\
$4^{1}{ }^{1} \mathrm{~B}_{2}$ & & & $1.25(0.39)$ & $1.06(0.54)$ \\
& & $\mathrm{C}_{101} \mathrm{H}_{103}{ }^{+}$ & & \\
$1^{1} \mathrm{~B}_{2}$ & $0.44(7.79)$ & $0.38(5.92)$ & $0.54(5.08)$ \\
$2{ }^{1} \mathrm{~B}_{2}$ & $0.65(6.62)$ & $0.64(4.90)$ & $0.81(8.16)$ \\
$3{ }^{1} \mathrm{~B}_{2}$ & $0.76(2.80)$ & $0.75(0.78)$ & $0.83(0.13)$ \\
$4{ }^{1} \mathrm{~B}_{2}$ & $0.87(0.57)$ & $0.86(2.51)$ & $0.99(1.08)$ \\
$5{ }^{1} \mathrm{~B}_{2}$ & $1.02(0.48)$ & $1.04(1.08)$ & $1.12(1.16)$
\end{tabular}

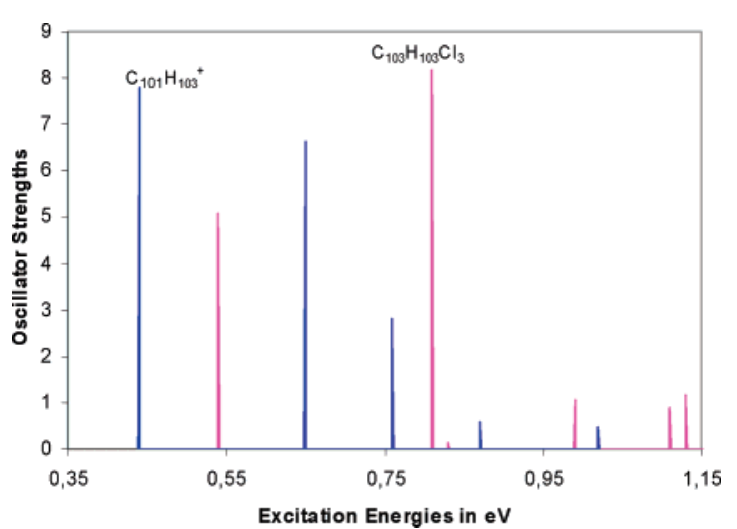

Figure 17. UV-spectra of $\mathrm{C}_{101} \mathrm{H}_{103}{ }^{+}$and of $\mathrm{C}_{101} \mathrm{H}_{103}-\mathrm{Cl}_{3}$ with pure TDDFT.

are the same interchain excitations as in the absence of counterions in all systems investigated. Thus the effect of the counterions on the spectra is indirect, influencing geometric and electronic structures and therefore transition energies and oscillator strengths of the polyenes.

In Table 5 excitation energies of $\mathrm{C}_{41} \mathrm{H}_{43}-\mathrm{Cl}_{3}, \mathrm{C}_{69} \mathrm{H}_{71}-$ $\mathrm{Cl}_{3}$, and $\mathrm{C}_{101} \mathrm{H}_{103}-\mathrm{Cl}_{3}$ are compared with those of the corresponding naked cations. In Figure 17 spectra are simulated for $\mathrm{C}_{101} \mathrm{H}_{103}-\mathrm{Cl}_{3}$ and $\mathrm{C}_{101} \mathrm{H}_{103}{ }^{+}$. In all cases there is a blue shift due to the presence of a counterion. The energies of the first allowed transitions in the presence of the counterion differ by up to $0.10 \mathrm{eV}$ from those of the naked cations. The differences are a little larger for the higher energy transitions. The main difference between complexes and cations is that the oscillator strengths of the first transitions decrease and those of the higher energy transitions increase in the presence of counterions. Thus the maximum absorption shifts to shorter wavelengths.

Counterions have a localizing effect on geometry and electronic structure. To separate the two effects, the coun-

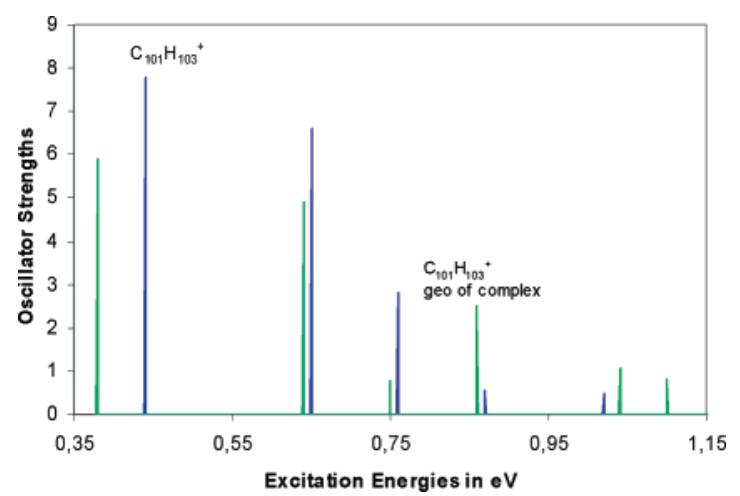

Figure 18. UV-spectra of $\mathrm{C}_{101} \mathrm{H}_{103}{ }^{+}$at its optimized geometry and at the geometry of $\mathrm{C}_{101} \mathrm{H}_{103}-\mathrm{Cl}_{3}$ after removing the counterion with pure TDDFT.

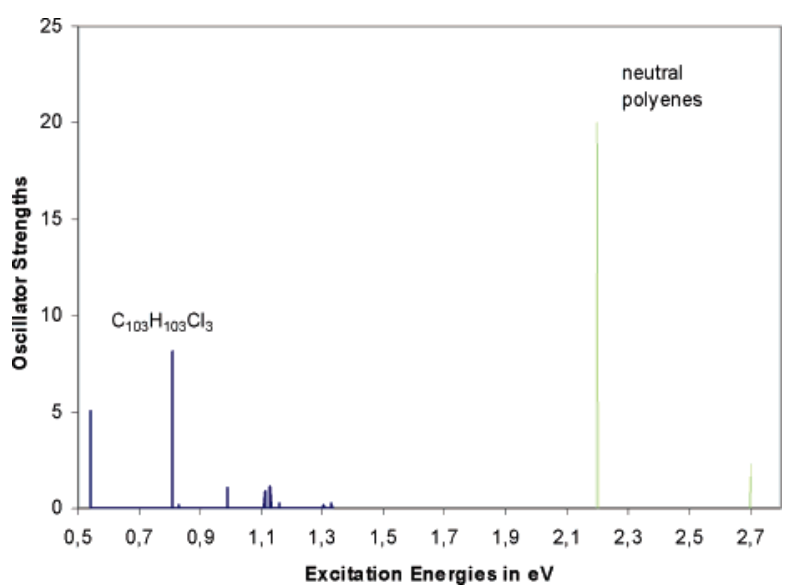

Figure 19. Comparison of the spectrum predicted with pureTDDFT for $\mathrm{C}_{101} \mathrm{H}_{103}-\mathrm{Cl}_{3}$ and that for neutral polyenes obtained with TDHF.

terions were removed from the complexes, and spectra were recalculated for the cations employing the geometries of the complexes. For $\mathrm{C}_{41} \mathrm{H}_{43}{ }^{+}$the delocalized pure-DFT geometry was used in addition. The data are included in Table 5. Using the delocalized pure-DFT geometry does not change the spectrum compared to the one based on the DFT-hybrid structure. Using the geometries of the complexes leads to a slight red-shift of the first peak and an increase in oscillator strength of the higher lying peaks. In Figure 18 spectra of $\mathrm{C}_{101} \mathrm{H}_{103}{ }^{+}$with different geometries are compared. The difference between the spectra with localized and delocalized defects is not dramatic. The first allowed peak is red-shifted by $0.06 \mathrm{eV}$, and the oscillator strengths of peaks four increase while those of peaks 1, 2, and 3 decrease. This result suggests that electron phonon coupling is not crucial to explain the spectral changes during doping. The bigger change occurs in the electronic structure and is caused by the presence of the counterion as can be seen in Figure 17.

The last entry in Table 5 for $\mathrm{C}_{101} \mathrm{H}_{103}-\mathrm{Cl}_{3}$ should resemble the excitation energies of a lightly doped isolated PA chain quite well. Therefore the spectrum of $\mathrm{C}_{101} \mathrm{H}_{103}-\mathrm{Cl}_{3}$ is compared to the TDHF spectrum typical for neutral polyenes in Figure 19. TDHF $\lambda_{\max }$ values of neutral polyenes converge to $\sim 2.2 \mathrm{eV}$. The $\lambda_{\max }$ values for example are $2.24 \mathrm{eV}$ for 
$\mathrm{C}_{88} \mathrm{H}_{90}$ and 2.17 for $\mathrm{C}_{162} \mathrm{H}_{164}$. Oscillator strengths for long chain polyenes are huge with values of up to 40 for $\mathrm{C}_{162} \mathrm{H}_{164}$. For cations oscillator strengths go through a maximum with increasing chain lengths as oscillator strengths shift from lower to higher energy transitions. Therefore the predicted spectral change upon doping (Figure 19) agrees well with experiment which shows a decrease of the intense $1.8 \mathrm{eV}$ peak of neutral PA and the development of a much weaker and rather broad feature peaking at around $0.7 \mathrm{eV} .^{2}$

\section{Conclusions}

In this investigation the theoretical level necessary to obtain excitation energies of closed- and open-shell polyene cations with up to $101 \mathrm{CH}$ units was established, and spectral features of polyene monocations were examined in the absence and in the presence of a $\mathrm{Cl}_{3}{ }^{-}$counterion.

- Comparison of CASSCF, MP2, and DFT methods shows that geometries of closed-shell polyene cations can be obtained with DFT-hybrid functionals (30\% of HF exchange) with the same accuracy as with MP2. This holds with respect to bond lengths alternation and defect size. For evennumbered open-shell cations, spin-contamination increases with increasing chain lengths with the DFT-hybrid functional and leads to deterioration of the results. Pure DFT is consistent for closed- and open-shell systems, but BLA is too small since double lengths are too large.

- Potential energy surfaces of polyene cations are very flat. The energy differences per repeat unit for structures with localized and delocalized defects are so small that the MP2 level of theory is probably not sufficient to determine the accurate defect size. Defect sizes are expected therefore to depend strongly on environmental effects, such as counterions, medium, and crystal packing.

- For excited-state calculations of closed-shell cations, TDDFT gives reliable values that do not deteriorate at long chain lengths like for neutral species. Pure DFT and DFThybrid lead to very similar excitation energies for the first allowed excited state. Higher lying excited states are obtained at lower energy with pure DFT than with DFT hybrid.

- Because of spin-contamination, hybrid functionals lead to qualitatively wrong oscillator strengths for open-shell polyene cations longer than $28 \mathrm{CH}$ units. Pure DFT gives similar results for open- and closed-shell cations at all chain lengths and compares well with experiment and MRMP for butadiene through decapentaene cations.

- The lowest allowed excited state has the same energy and the same oscillator strength for odd- and even-numbered polyene cations. The weak feature that occurs only for openshell systems has low oscillator strength at all chain lengths. Thus odd-numbered polyene cations are good models for PA.

- With increasing chain lengths additional allowed states with high oscillator strengths and only slightly higher energies are predicted. This might lead to a broad absorption or several very closely spaced features in the UV spectrum of lightly doped PA. Conjugation lengths of about 40-50 $\mathrm{CH}$ units are required for these high additional transitions to achieve significant oscillator strengths.
- Counterions have a localizing effect and decrease the size of the defect by about $40 \mathrm{CH}$ units in the longest system considered here with $101 \mathrm{CH}$ units. The defect is still predicted to be about $40 \mathrm{CH}$ units wide. There is a midgap state for long polyene cations in the absence of counterions when the defect spreads over $80 \mathrm{CH}$ units. Thus defect localization is not necessary for producing a midgap state.

- The energies of the first five excited states of polyene cations are practically independent of the geometry used. The sub-band transition in polyene cations is obtained in structures with localized and with delocalized defects at the same energy. Thus the sub-band feature in doped PA seems to be due to changes in the electronic rather than in the geometric structure.

- Localization influences oscillator strengths, shifting intensity from the HOMO-LUMO transition to higher lying excited states. This trend is further enhanced when a counterion is included explicitly. Excitations between polyene cation and counterion have low oscillator strengths.

Acknowledgment. This work is supported by TÜBITAK (TBAG-2461) and by Bilkent University. I would like to thank Prof. Stefan Grimme for helpful discussions and Dennis Salzner for writing a program that extracts orbital energies from G03 output files for plotting.

\section{References}

(1) Naarmann, C. H.; Theophilou, N. Synth. Met. 1987, 22, 1.

(2) Fincher, C. R., Jr.; Peebles, D. L.; Heeger, A. J.; Druy, M. A.; Matsamura, Y.; MacDiarmid, A. G.; Shirakawa, H.; Ikeda, S. Solid State Commun. 1978, 27, 489.

(3) Fincher, C. R., Jr.; Ozaki, M.; Tanaka, M.; Peebles, D.; Lauchlan, L.; Heeger, A. J. Phys. Rev. B 1979, 20, 1589.

(4) Fincher, C. R., Jr.; Ozaki, M.; Heeger, A. J.; MacDiarmid, A. G. Phys. Rev. B 1979, 19, 4140.

(5) Patil, A. O.; Heeger, A. J.; Wudl, F. Chem. Rev. 1988, 88, 183.

(6) Yakushi, K.; Lauchlan, L. J.; Clarke, T. C.; Street, G. B. J. Chem. Phys. 1983, 79, 4774.

(7) Su, W.-P.; Schrieffer, J. R.; Heeger, A. J. Phys. Rev. Lett. 1979, 42, 1698.

(8) Su, W. P.; Schrieffer, J. R.; Heeger, A. J. Phys. Rev. B 1980, 22, 2099.

(9) Su, W.-P. Solid State Commun. 1980, 35, 899.

(10) Bally, T.; Roth, K.; Tang, W.; Schrock, R. R.; Knoll, K.; Park, L. Y. J. Am. Chem. Soc. 1992, 114, 2440.

(11) Zinger, B.; Mann, K. R.; Hill, M. G.; Miller, L. L. Chem. Mater. 1992, 4, 1113.

(12) Hill, M. G.; Penneau, J.-F.; Zinger, B.; Mann, K. R.; Miller, L. L. Chem. Mater. 1992, 4, 1106.

(13) Bäuerle, P.; Segelbacher, U.; Maier, A.; Mehring, M. J. Am. Chem. Soc. 1993, 115, 10217.

(14) Furukawa, Y. J. Phys. Chem. 1996, 100, 15644.

(15) Kawashima, Y.; Nakayama, K.; Nakano, H.; Hirao, H. Chem. Phys. Lett. 1997, 267, 82.

(16) Ye, A.; Shuai, Z.; Kwon, O.; Brédas, J. L.; Beljonne, D. J. Chem. Phys. 2004, 121, 5567. 
(17) Rubio, M.; Ortí, E.; Pou-Amerigo, R.; Merchán, M. J. Phys. Chem. A 2001, 105, 9788.

(18) Keszthelyi, T.; Grage, M. M.-L.; Offersgard, J. F.; Wilbrandt, R.; Svendsen, C.; Sonnich Mortensen, O.; Pedersen, J. K.; Jensen, H. J. A. J. Phys. Chem. A 2000, 104, 2808.

(19) Brédas, J. L.; Chance, R. R.; Silbey, R. J. Phys. Chem. 1981, $85,756$.

(20) Brédas, J. L.; Chance, R. R.; Silbey, R. Phys. Rev. B 1982, 26, 5843.

(21) Campbell, D. K.; Bishop, A. R. Nucl. Phys. B 1982, 200, 297.

(22) Campbell, D. K.; Bishop, A. R.; Fesser, K. Phys. Rev. B 1982, 26, 6862 .

(23) Boudreaux, D. S.; Chance, R. R.; Brédas, J. L.; Silbey, R. Phys. Rev. B 1983, 28, 6927.

(24) Brédas, J. L.; Scott, J. C.; Yakushi, K.; Street, G. B. Phys. Rev. B 1984, 30, 1023.

(25) Brédas, J. L.; Thémans, B.; Fripiat, J. G.; André, J.-M.; Chance, R. R. Phys. Rev. B 1984, 29, 6761.

(26) Brédas, J. L. J. Mol. Struct. (Theochem) 1984, 107, 169.

(27) Brédas, J. L.; Street, G. B. Acc. Chem. Res. 1985, 18, 309.

(28) Kivelson, S.; Heeger, A. J. Phys. Rev. Lett. 1985, 55, 308.

(29) Heeger, A. J.; Kivelson, S.; Schrieffer, J. R.; Su, W.-P. Rev. Mod. Phys. 1988, 60, 781.

(30) Stafström, S.; Brédas, J. L. Phys. Rev. B 1988, 38, 4180.

(31) Villar, H. O.; Dupuis, M.; Clementi, E. Phys. Rev. B 1988, 37,2520 .

(32) Ehrendorfer, C.; Karpfen, A. J. Phys. Chem. 1994, 98, 7492.

(33) Ehrendorfer, C.; Karpfen, A. J. Chem. Phys. 1995, 99, 10196.

(34) Ehrendorfer, C.; Karpfen, A. J. Phys. Chem. 1995, 99, 5341.

(35) Champagne, B.; Spassova, M. Phys. Chem. Chem. Phys. 2004, 6, 3167.

(36) Tol, A. J. W. Chem. Phys. 1996, 208, 73.

(37) Irle, S.; Lischka, H. J. Chem. Phys. 1997, 107, 3021.

(38) Shimoi, Y.; Abe, S. Phys. Rev. B 1994, 50, 14781.

(39) Brocks, G. J. Chem. Phys. 2000, 112, 5353.

(40) Scherlis, D. A.; Marzari, N. J. Phys. Chem. B 2004, 108, 17791.

(41) Hirata, S.; Head-Gordon, M. Chem. Phys. Lett. 1999, 302, 375.

(42) Dreuw, A.; Head-Gordon, M. Chem. Rev. 2005, 105, 4009.

(43) Salzner, U. Curr. Org. Chem. 2004, 8, 569.

(44) Salzner, U. Conjugated Organic Polymers: From Bulk to Molecular Wire. In Handbook of Theoretical and Computational Nanotechnology; Rieth, M., Schommers, W., Eds.; ASP: 2006; Vol. 8, Chapter 5, p 203.

(45) Hsu, C.-P.; Hirata, S.; Head-Gordon, M. J. Phys. Chem. A 2001, 105, 451.

(46) Cai, Z.-L.; Sendt, K.; Reimers, J. R. J. Chem. Phys. 2002, $117,5543$.

(47) Grimm, S.; Nonnenberg, C.; Frank, I. J. Chem. Phys. 2003, 119, 11574.

(48) Cundari, T. R.; Stevens, W. J. J. Chem. Phys. 1993, 98, 5555.
(49) Stevens, W.; Basch, H.; Krauss, J. J. Chem. Phys. 1984, 81, 6026.

(50) Stevens, W. J.; Krauss, M.; Basch, H.; Jasien, P. G. Can. J. Chem. 1992, 70, 612.

(51) Salzner, U.; Karalti, O.; Durdagi, S. J. Mol. Model. 2006, $12,687$.

(52) Salzner, U.; Lagowski, J. B.; Pickup, P. G.; Poirier, R. A. J. Comput. Chem. 1997, 18, 1943.

(53) Salzner, U.; Lagowski, J. B.; Pickup, P. G.; Poirier, R. A. J. Phys. Chem. 1998, 102, 2572.

(54) Salzner, U.; Lagowski, J. B.; Poirier, R. A.; Pickup, P. G. Synth. Met. 1998, 96, 177.

(55) Møller, C.; Plesset, M. S. Phys. Rev. 1934, 46, 618.

(56) Hegarty, D.; Robb, M. A. Mol. Phys. 1979, 38, 1975.

(57) Eade, R. H. E.; Robb, M. A. Chem. Phys. Lett. 1981, 83, 362.

(58) Schlegel, H. B.; Robb, M. A. Chem. Phys. Lett. 1982, 93, 43.

(59) Bernardi, F.; Bottini, A.; McDougall, J. J. W.; Robb, M. A.; Schlegel, H. B. Far. Symp. Chem. Soc. 1984, 19, 137.

(60) Frisch, M. J.; Ragazos, I. N.; Robb, M. A.; Schlegel, H. B. Chem. Phys. Lett. 1992, 189, 524.

(61) Yamamoto, N.; Vreven, T.; Robb, M. A.; Frisch, M. J.; Schlegel, H. B. Chem. Phys. Lett. 1996, 250, 373.

(62) Becke, A. D. J. Chem. Phys. 1993, 98, 5648.

(63) Perdew, J. P. Phys. Rev. B 1986, 33, 8822.

(64) Becke, A. D. Phys. Rev. A 1988, 38, 3098.

(65) Bauernschmitt, R.; Ahlrichs, R. Chem. Phys. Lett. 1996, 256, 454.

(66) Casida, M. E.; Jamorski, C.; Casida, K. C.; Salahub, D. R. J. Chem. Phys. 1998, 108, 4439.

(67) Stratmann, R. E.; Scuseria, G. E.; Frisch, M. J. J. Chem. Phys. 1998, 109.

(68) Choi, C. H.; Kertesz, M.; Karpfen, A. J. Chem. Phys. 1997, 107, 6712 .

(69) Frisch, M. J.; Trucks, G. W.; Schlegel, H. B.; Scuseria, G. E.; Robb, M. A.; Cheeseman, J. R.; Montgomery, J., J. A.; Vreven, T.; Kudin, K. N.; Burant, J. C.; Millam, J. M.; Iyengar, S. S.; Tomasi, J.; Barone, V.; Mennucci, B.; Cossi, M.; Scalmani, G.; Rega, N.; Petersson, G. A.; Nakatsuji, H.; Hada, M.; Ehara, M.; Toyota, K.; Fukuda, R.; Hasegawa, J.; Ishida, M.; Nakajima, T.; Honda, Y.; Kitao, O.; Nakai, H.; Klene, M.; Li, X.; Knox, J. E.; Hratchian, H. P.; Cross, J. B.; Adamo, C.; Jaramillo, J.; Gomperts, R.; Stratmann, R. E.; Yazyev, O.; Austin, A. J.; Cammi, R.; Pomelli, C.; Ochterski, J. W.; Ayala, P. Y.; Morokuma, K.; Voth, G. A.; Salvador, P.; Dannenberg, J. J.; Zakrzewski, V. G.; Dapprich, S.; Daniels, A. D.; Strain, M. C.; Farkas, O.; Malick, D. K.; Rabuck, A. D.; Raghavachari, K.; Foresman, J. B.; Ortiz, J. V.; Cui, Q.; Baboul, A. G.; Clifford, S.; Cioslowski, J.; Stefanov, B. B.; Liu, G.; Liashenko, A.; Piskorz, P.; Komaromi, I.; Martin, R. L.; Fox, D. J.; Keith, T.; Al-Laham, M. A.; Peng, C. Y.; Nanayakkara, A.; Challacombe, M.; Gill, P. M. W.; Johnson, B.; Chen, W.; Wong, M. W.; Gonzales, C.; Pople, J. A. Gaussian 03; Revision C. 02 ed.; Gaussian, Inc.: Pittsburgh, 2003. 
(70) Frisch, M. J.; Trucks, G. W.; Schlegel, H. B.; Scuseria, G. E.; Robb, M. A.; Cheeseman, J. R.; Montgomery, J., J. A.; Vreven, T.; Kudin, K. N.; Burant, J. C.; Millam, J. M.; Iyengar, S. S.; Tomasi, J.; Barone, V.; Mennucci, B.; Cossi, M.; Scalmani, G.; Rega, N.; Petersson, G. A.; Nakatsuji, H.; Hada, M.; Ehara, M.; Toyota, K.; Fukuda, R.; Hasegawa, J.; Ishida, M.; Nakajima, T.; Honda, Y.; Kitao, O.; Nakai, H.; Klene, M.; Li, X.; Knox, J. E.; Hratchian, H. P.; Cross, J. B.; Bakken, V.; Adamo, C.; Jaramillo, J.; Gomperts, R.; Stratmann, R. E.; Yazyev, O.; Austin, A. J.; Cammi, R.; Pomelli, C.; Ochterski, J. W.; Ayala, P. Y.; Morokuma, K.; Voth, G. A.; Salvador, P.; Dannenberg, J. J.; Zakrzewski, V. G.; Dapprich, S.; Daniels, A. D.; Strain, M. C.; Farkas, O.; Malick, D. K.; Rabuck, A. D.; Raghavachari, K.; Foresman, J. B.; Ortiz, J. V.; Cui, Q.; Baboul, A. G.; Clifford, S.; Cioslowski, J.; Stefanov, B. B.; Liu, G.; Liashenko, A.; Piskorz, P.; Komaromi, I.; Martin, R. L.; Fox, D. J.; Keith, T.; Al-Laham, M. A.; Peng, C. Y.; Nanayakkara, A.; Challacombe, M.; Gill, P. M. W.; Johnson, B.; Chen, W.; Wong, M. W.; Gonzales, C.; Pople, J. A. Gaussian 03; Revision D. 01 ed.; Gaussian, Inc.: Wallingford, 2004.

(71) Cramer, C. J. Essentials of Computational Chemistry, Theories and Models; John Wiley: Chichester, 2004.

(72) Ciofini, I.; Adamo, C.; Chermette, H. J. Chem. Phys. 2005, 123, 121102.

(73) Jacquemin, D.; Femenias, A.; Chermette, H.; André, J.-M.; Perpète, E. A. J. Phys. Chem. A 2005, 109, 5734.

(74) Jacquemin, D.; Perpète, E. A.; Ciofini, I.; Adamo, C. Chem. Phys. Lett. 2005, 405, 376.

(75) Lee, C.; Yang, W.; Parr, R. G. Phys. Rev. B 1988, 37, 785.
(76) Fincher, C. R.; Chen, C.-E.; Heeger, A. J.; MacDiarmid, A. G.; Hastings, J. B. Phys. Rev. Lett. 1982, 48, 100.

(77) Yannoni, C. S.; Clarke, T. C. Phys. Rev. Lett. 1983, 51, 1191.

(78) Ferraro, J. R.; Hill, S.; Stout, P.; Furlani, A.; Polzonetti, G.; Russo, M. V. Appl. Spectosc. 1991, 45, 932.

(79) Reed, E. A.; Curtiss, L. A.; Weinhold, F. Chem. Rev. 1988, $88,899$.

(80) Bally, T.; Hrovat, D. A.; Thatcher Borden, W. Phys. Chem. Chem. Phys. 2000, 2, 3363.

(81) Serrano-Andrés, L.; Merchán, M.; Nebot-Gil, I.; Lindh, R.; Roos, B. O. J. Chem. Phys. 1993, 98, 3151.

(82) Serrano-Andrés, L.; Lindh, R.; Roos, B. O.; Merchán, M. J. Phys. Chem. 1993, 97, 9360.

(83) Nakayama, K.; Nakano, H.; Hirao, K. Int. J. Quantum. Chem. 1998, 66, 157.

(84) Bally, T.; Nitsche, S.; Roth, K.; Haselbach, E. J. Am. Chem. Soc. 1984, 106, 3927.

(85) Cronstrand, P.; Christiansen, O.; Norman, P.; Ågren, H. Phys. Chem. Chem. Phys. 2001, 3, 2567.

(86) Dreuw, A.; Head-Gordon, M. J. Am. Chem. Soc. 2004, 126, 4007.

(87) Dreuw, A.; Weisman, J. L.; Head-Gordon, M. J. Chem. Phys. 2003, 119, 2943.

(88) Parac, M.; Grimme, S. Chem. Phys. 2003, 292, 11.

(89) D'Amico, K. L.; Manos, C.; Christensen, R. L. J. Am. Chem. Soc. 1980, 102, 1777.

CT600223F 